Palimpsesto Vol. 11, № 18 (enero-junio, 2021): 34-61

Universidad de Santiago de Chile, ISSN 0718-5898

Bruno Rojas

Universidad de Chile

bruno.rojas.s@ug.uchile.cl

\title{
Romper las fronteras. Las luchas de las organizaciones de migrantes y la emergencia de una reivindicación antirracista (1998-2018, Santiago)* $^{*}$
}

\author{
Break the Borders. The Struggles of Migrant Organizations and the \\ Emergence of an Anti-racist Claim (1998-2018, Santiago)
}

\begin{abstract}
Resumen
Desde mediados de los noventa la migración latinoamericana y caribeña que ha arribado a Chile ha buscado integrarse a la vida social en nuestras ciudades. En Santiago, las comunidades de migrantes tuvieron que hacer frente a una serie de violencias sociales y procesos de exclusión a partir de una serie prácticas de racialización y desciudadanización, constituyendo para insertarse socialmente una heterogeneidad de redes de apoyo y organizaciones sociales. En este artículo se afirma la necesidad de cuestionar ciertos marcos analíticos para comprender la agencia de los migrantes ante los procesos de racialización y contribuye en este sentido explorando las dinámicas organizativas y reivindicativas de las organizaciones de migrantes. En este contexto, este artículo explora desde un enfoque sociohistórico los procesos organizativos, la acción colectiva y los marcos reivindicativos de las organizaciones de migrantes en Santiago desde fines de los noventas hasta el 2018. Seguimos así una línea de desarrollo de estas organizaciones que pasaron de ser espacios de apoyo mutuo para su inserción social conducidas por refugiados políticos peruanos, hasta el desarrollo de organizaciones sociales y sectoriales, madurando política y organizacionalmente en procesos de articulación que han llegado a tener escala nacional y vinculaciones con otros movimientos sociales. Proceso en el cual han levantado una serie de demandas para terminar con las exclusiones, discriminaciones y el racismo que enfrentan sus comunidades, enmarcando sus luchas en un discurso sobre los derechos humanos que extienda su reconocimiento a todos los habitantes sin importar nacionalidad ni color de piel, teniendo en su agencia un rol democratizador en la sociedad chilena.
\end{abstract}

Palabras claves: Organizaciones de migrantes, antirracismo, luchas migrantes, agencia colectiva, marcos reivindicativos.

${ }^{*}$ Este trabajo tiene su origen en el informe final para la obtención del grado Licenciatura en Historia por la Universidad de Chile, guiado por la Doctora Claudia Zapata. Departamento de Ciencias Históricas, Facultad de Filosofía y Humanidades, 2019. Esta investigación no recibió financiamiento. 


\begin{abstract}
Since the mid-nineties, the Latin American and Caribbean migration that has arrived in the country has sought to integrate into social life in our cities. In Santiago, migrant communities had to face a series of social violence and exclusion processes based on a series of racialization and de-citizenization practices, constituting a social heterogeneity of support networks and social organizations. This article affirms the need to question certain analytical frameworks in order to understand the agency of migrants in the face of racialization processes and contribute in this sense by exploring the organizational and demands dynamics of migrant organizations. In this context, this article explores from a sociohistorical perspective a line of development of these organizations that went from being spaces of mutual support for their social insertion led by peruvian political refugees, to the development of social and sectoral organizations, maturing politically and organizationally in articulation processes that have come to have a national scale and links with other social movements. Process in which they have raised a series of claims to end the exclusions and racism faced by their communities, framing their struggles in a discourse on human rights that extends its recognition to all inhabitants regardless of nationality or skin color, having in his agency a democratizing role in Chilean society.
\end{abstract}

Keywords: Migrant organizations, anti-racism, migrant struggles, collective agency, claims frameworks.

\title{
Introducción
}

Con la globalización neoliberal, las transformaciones en los flujos y los ciclos migratorios han transformado las dinámicas culturales y políticas de los países latinoamericanos (Radovich, 2006). Si en el Norte global han imperado políticas de control y seguridad frente a los trabajadores migrantes y sus familias (Sassen, 2013), a partir de la última década del siglo XX, distintos analistas han observado un cambio en el patrón migratorio regional, diversificándose internamente en términos sociales y culturales, aumentando la migración entre los países latinoamericanos (Stefoni 2017; Mora, 2008). Sin embargo, los procesos de integración y reconocimiento de estas nuevas poblaciones han sido inconsistentes y problemáticos. De hecho, las formas de regulación político administrativas que rigen los procesos de producción de ciudadanías en países de creciente inmigración, como Chile y Brasil, se han tornado cada vez más excluyentes (Thayer, 2016).

En Chile, la migración intrarregional enfrentó una serie de cambios desde mediados de los noventa, pasando de tener su origen en países transfronterizos a progresivamente atraer personas de países como Colombia, Haití, Venezuela y República Dominicana; siendo caracterizada como una migración feminizada y siendo su inserción laboral segmentada (Mora, 2009; Stefoni, \& Stang, 2017). Pese a este crecimiento, los diferentes pactos gobernantes no han implementado una política migratoria sistemática que rija los procesos de inclusión social, política y cultural para los extranjeros, habiendo el Estado firmado una serie de acuerdos administrativos y tratados internacionales que así lo mandatan. La orientación negligente del Estado chileno en esta materia 


\section{Bruno Rojas}

ha operado bajo la lógica que algunas autoras han llamado de la "política de la no política" (Stefoni, 2011). Falta de legislación en términos de derechos e inserción, que se contrapone a la sobrerregulación y la burocratización del control sobre las trayectorias migratorias regidas aún por el D.L $\mathrm{N}^{\circ} 1094$ de origen dictatorial, extendiendo el periodo de transitoriedad migratoria hacia la regularización definitiva durante años (Thayer 205), lo que termina sedimentando una irregularidad estructural al sistema migratorio (Stang, 2012). Procesos de "extranjerización permanente" (Benhabib, 2005) que la literatura ha relacionado con "procesos de desciudadanización" (Thayer, 2015; Goldring \& Landolot, 2013) en términos de pérdida de derechos y reconocimiento.

Estas exclusiones de tipo civil y político se articulan a la discriminación y los "procesos de racialización" y sexualización que se desarrollan hacia los migrantes en la sociedad chilena (Staab y Hill Maher, 2006; Tijoux, 2011). Según la literatura del campo de los estudios migratorios, la figura social del «inmigrante» operaría como un tipo de marcación estigmatizante sobre los cuerpos de la migración latinoamericana en Chile, que esencializa, reduce y objetiva a diferentes comunidades e individuos provenientes de diferentes países de la región (particularmente Haití, República Dominicana, Bolivia, Perú y Colombia), agrupándolos como el límite interno de la nación. De ese modo, los migrantes sería tales en tanto precisan su expulsión como "Otro" extraño, peligroso y enemigo. Siendo asociados a figuras sociales estigmatizadoras como el delincuente, el narcotraficante o el terrorista, o a ciertas características como la flojera o la promiscuidad. Alteridad que afirma y cristaliza el "principio de identidad" de la chilenidad a partir de la exclusión de este "Otro" del lazo comunitario de la política y su régimen de derechos. Los migrantes racializados serían objetivados en el mero ámbito de lo económico o de la particularidad exótica (Tijoux, 2013, pp. 190-191).

A partir de esta construcción del migrante como "alteridad" negada, la consideración analítica de la racialización como categoría estructurante de la sociedad ha permitido visibilizar aspectos de la estratificación y las inequidades sociales constituidas por distintos mecanismos de exclusión y discriminación (Stefoni \& Stang, 2017). Así, estos estudios han explorado la inserción de las y los trabajadores migrantes en mercados laborales segmentados que los concentran en labores precarizadas de baja productividad, configurándose fronteras materiales y simbólicas para su integración y reconocimiento social (Stefoni et al, 2017). Expresándose también en el proceso de producción de ciudad, donde debido a la dinámica de precios y la condición extendida de irregularidad en los contratos, serían forzados a concentrarse en comunas con parques residenciales deteriorados, con bajas condiciones de habitabilidad tanto del pericentro urbano como de comunas periféricas, que comienzan a ser estigmatizadas en tanto "barrios migrantes" (Segura y Bijit, 2014).

¿Pero cómo actúan los migrantes frente a estas experiencias de exclusión y menosprecio (Honneth)? ¿Cuáles son sus capacidades de agencia respecto al racismo? Si seguimos a los estudios migratorios, con un concepto del racismo como un discurso que orienta y define las formas de interacción entre chilenos y migrantes, determinando formas de estigmatización ¿cuáles son las capacidades agenciales que reconocemos en los migrantes? Para problematizar esta concepción, puede ser útil desestabilizar tanto los marcos analíticos con los que este campo ha estudiado el racismo hacia los migrantes, como contrastar sus nociones fundamentales con las formas de acción colectiva que los mismos migrantes han desarrollado, sus interacciones con otros actores y sus reivindicaciones de reconocimiento que cuestionan los marcos que definen a la ciudadanía. 


\section{Racismo y la agencia de los inmigrantes}

Sin desconsiderar los avances que ha producido el campo de los estudios migratorios, los marcos analíticos elaborados para estudiar el problema de la exclusión, el racismo y la inserción de los inmigrantes a la sociedad chilena, pese a sus debates y heterogeneidades internas, presentan desde mi punto de vista dos limitaciones relacionadas: una categorial y otra epistemológica.

En términos categoriales, gran parte de estos estudios sobre el racismo y la migración movilizan una idea de alteridad que -como reconocen autocríticamente Stefoni y Stang- se vincula a los estudios poscoloniales del Norte global, concepción que ha influido en los investigadores para pensar a los inmigrantes mediante unos conceptos esencialistas y estáticos de diferencia y la alteridad cultural. Así, la idea misma del migrante es entendida como un epifenómeno de la construcción discursiva que permitiría en tanto "Otro" la afirmación y legitimación de la chilenidad y del Estado-nación en los procesos de racialización (Bellard, 2016). Alteridad que reintroduciría la lógica colonial en la afirmación de la nacionalidad homogénea del Estado criollo y su proyecto civilizatorio "blanco", anidado desde su origen histórico, y que habría trascendido en las repúblicas independizadas políticamente de la dominación europea (Tijoux \& Córdova, 2015; Stefoni \& Stang, 2017).

Celebrando que cierto campo de las ciencias sociales busque hacerse cargo de la herencia colonial en las instituciones y prácticas de nuestro presente, no puedo sino apuntar para aportar en este sentido la "concepción esencializada de la alteridad" con la que ese proceso de construcción de otredad queda registrado en las investigaciones, pues al definir en términos dicotómicos la relación entre chilenos y migrantes, introducen veladamente un concepto cerrado del migrante y una concepción binaria de la diferencia cultural, como una oposición firme entre el adentro y el afuera (Hall, 2003). En efecto, este binarismo descansaría en un concepto del "inmigrante" como portador de una diferencia cultural radical (Zapata, 2008), en donde éstos serían situados en el lugar del eslabón inmediatamente subordinado y exterior-interior en su relación con una chilenidad también definida esencialmente por la actualización de su lugar de dominación, perdiéndose en ambos casos la historicidad, la inestabilidad, las jerarquías internas a ambas categorías, las diferencias específicas y las impurezas de las formaciones subjetivas asociadas al proceso histórico real del racismo, donde los procesos de encuentro e interculturalidad práctica son procesos emergentes pese a las constricciones estructurales de la lógica de estigmatización racial. De ese modo, más que hablar de la relación entre chilenos y migrantes, habría que estudiar empíricamente los casos, describir las categorías históricas de sujeto que podrían llegar a expresar sus capacidades de negociar, aceptar, resignificar, resistir o negar los "efectos de poder" del discurso racista en su práctica social y en su interacción. Cambio en los marcos analíticos que nos permitiría estudiar a la alteridad no como una categoría del ser, sino como un proceso histórico de alterización producto de la disputa entre fuerzas que se forman y se constriñen a diferentes escalas e históricamente, que se expresan situadamente (Briones, 2005).

Esto nos lleva a relevar el problema epistemológico que leo tras esta concepción de diferencia cultural radical, tan difundida en este campo investigativo, en donde las estructuras se sitúan como ontológica y epistemológicamente determinantes frente a los actores, sin considerar el carácter emergente de los procesos de diferenciación y diversidad cultural, así como la 


\section{Bruno Rojas}

irreductibilidad de la capacidad de agencia para modificar, reinterpretar, negociar, resistir, recrear esas estructuras en el proceso de constitución de los sujetos, a partir de su acción, interacción y su reflexividad. Problema que se expresa como una verdadera frontera teórica para pensar el problema del racismo hacia los migrantes y las formas heterogéneas que emergen en los procesos de "convivencia" entre distintos grupos etnonacionales (Ramírez et al 2021).

Creo que el concepto de racismo tras los estudios migratorios, como discurso de poder que articula las disposiciones y orientaciones para que los sujetos de la chilenidad reproduzcan el racismo, al modo de un mecanismo para reproducir el sistema de actualización de la identidad nacional y el Estado, sitúan a los migrantes como meros objetos o cuerpos de la representación. Concepción que nos embriaga en el análisis de los modos de sujeción perdiendo de vista los procesos de convivencia, subjetivación y conflicto.

Apostando por un enfoque que recupere esta última dimensión de la subjetividad, queremos salir del análisis de la sujeción del discurso racista para pasar al análisis de la dimensión del campo de fuerzas en que se constituye la alteridad y la racialización, los procesos de constitución de antagonismo y formación de subjetividades, así como la capacidad de agencia y constitución de proyectos y alianzas contrahegemónicas que en ciertos contextos definidos por las relaciones de fuerza (Gramsci ver en Hall, 2006) adquieren capacidad morfogenética. No postulo aquí la defensa de una subjetividad sin anclaje estructural, sino que afirmo que una consideración crítica frente al fenómeno de la exclusión y la inserción de los migrantes en la sociedad chilena no debería perder de vista la particularidad de cada uno de estos niveles de la realidad social y, por tanto, de cómo el proceso social del encuentro intercultural emerge a partir de la vinculación en el tiempo de estructura y capacidades agenciales. (Archer, 2009) Y esta consideración es del todo relevante sobre todo cuando los mismos migrantes se han hecho parte de acciones colectivas y movimientos que no solo han desnaturalizado su condición particular de exclusión, sino que han aportado en procesos colectivos de impugnación en temas de trascendencia política que afectan al modo de estructurar el orden social.

En un intento de aproximarnos a estos problemas rompiendo con esta frontera teórica es que en este artículo exploramos la acción colectiva de las organizaciones de migrantes en Santiago a partir de las primeras organizaciones que se formaron para actuar sobre los problemas de inserción de la migración en la sociedad chilena. Siguiendo a autores que han destacado la capacidad accionalista de las asociaciones de migrantes (Stefoni, 2001; Luque Brazán 2002b; 2007a; 2007b; 2009), el poder transformador de los movimientos migratorios (Mezzadra, 2005) así como las "luchas migrantes" (Varela, 2015), recuperamos algunos trabajos que han explorado las experiencias de algunas organizaciones de migrantes (Bórquez y Salvo, 2015; Lobos 2017; Fernández y Herrera, 2017) para pesquisar su acción colectiva y sus marcos de sentido.

\section{Organizaciones migrantes, acción colectiva y marcos reivindicativos}

El presente artículo busca examinar la acción colectiva de las organizaciones de migrantes a partir de la relación entre repertorios de acción, demandas y sus marcos reivindicativos. Para ello, trabajaremos sobre una diferencia teórica fundamental entre las redes o comunidades migrantes y las organizaciones de migrantes. Las primeras, son entendidas como las dimensiones culturales, sociales y ecológicas de la inmigración en su proceso de inserción a la sociedad receptora, más allá de las particularidades individuales de trayectoria. Concepto que se basa en la 


\section{Bruno Rojas}

idea de las redes sociales en los estudios migratorios (Portes, 1995; Thayer Correa, 2013), pero que en tanto "comunidades" implica aquí un cierto grado de consistencia y establecimiento de relaciones en el tiempo a partir de las redes, normalmente fundadas en relaciones de parentesco, amistad, origen, por su vecindad en el territorio o por su ámbito laboral, pero que son extensibles en su formación y vinculación e implican lógicas de apoyo mutuo y reciprocidad en el proceso de inserción social. Por otro lado, aquí entenderemos a las organizaciones de migrantes como los sistemas de acción colectiva organizada de acuerdo con fines a influir en el proceso político o en el comportamiento social más general (Norris en Van Deth, 2001) anclados a la experiencia social de las comunidades migrantes y movilizando una categoría política de agregación en tanto migrantes o inmigrantes para referenciar sus acciones y discursos.

El objetivo de esta investigación es caracterizar la acción colectiva de las organizaciones de migrantes a partir de la relación entre las diferentes demandas que han levantado con sus repertorios de acción y protesta (Tilly, 2002). Buscando comprende esas acciones a partir no solo de su dimensión estratégica, sino que a partir de los frames con los que estos actores significan y diagnostican su entorno e instalan sus reivindicaciones en la sociedad. Siguiendo el enfoque del proceso político y el análisis de los marcos de acción colectiva, en este trabajo entenderemos por marcos reivindicativos a los esquemas de "enunciación" que operan como los horizontes comprensivos que le permiten a los actores entender y significar sus agravios colectivos orientando su acción colectiva, le dan sentido a sus repertorios y configuran su percepción sobre las coordenadas del campo de fuerzas para la formación de posibles alianzas (Tarrow, 1997).

En este sentido este trabajo entroniza con cierta sociología política de las "luchas migrantes" basadas en reivindicaciones que apelan a sus expectativas de reconocimiento (Thayer Correa, 2013) jurídico y social como ciudadanos plenos y sujetos de derechos a partir de su condición humana (Varela, 2016), interpelando al Estado y a la sociedad a partir de una crítica al racismo y la xenofobia, redefiniendo los marcos normativos del reconocimiento social y la definición imperante de ciudadanía.

\section{Consideraciones metodológicas}

Este artículo es fruto de una investigación cualitativa desarrollada a partir de un enfoque sociohistórico basada en revisión de prensa nacional, así como una serie de documentos de organizaciones de migrantes radicadas en Santiago. En particular, se recuperaron documentos de organizaciones como el Movimiento de Acción Migrantes, el Colectivo Sin Fronteras, Warmipura, entre otras. Por otro lado, realizamos una serie de entrevistas en profundidad a informantes clave, en particular a líderes y participantes activos de organizaciones de migrantes. La razón de estas entrevistas se fundó en el objetivo de poder entender los marcos de acción de las organizaciones, así como lograr entender sus repertorios de acción y sus demandas.

Del mismo modo, integramos una serie de observaciones participantes que realizamos desde un enfoque etnográfico, realizadas a partir de una participación en una colaboración junto al Movimiento de Acción Migrante entre los años 2017 y 2018. 


\section{Bruno Rojas}

\section{De refugiados políticos a organizaciones de migrantes}

La llegada de cientos de refugiados políticos peruanos en los noventa a Chile marca el comienzo de la experiencia del primer núcleo organizativo de migrantes peruanos en Chile (Avendaño, 1999). La presencia de representantes de ACNUR que estaban trabajando en el retorno de los exiliados chilenos, así como los contactos que desde el Perú tenían estos militantes con organizaciones de derechos humanos como la CODEPU y la Corporación AYUN y partidos de izquierda como el Partido Comunista y la Izquierda Cristiana, promovieron el refugio de militantes peruanos en Chile sirviendo de primer apoyo en el establecimiento de vínculos y redes a su arribo (Luque, 2009, pp. 102). Redes que fueron claves, sobre todo porque las condiciones de expulsión de estos refugiados eran normalmente respuestas súbitas a posibles encarcelamientos y persecuciones, llegando al país sin recursos económicos ni trabajo (Luque, 2009, p.11).

La Parroquia Italiana de la Orden Scalabriniana en 1994 generó un espacio de acogida para refugiados quienes junto a otros militantes de izquierda comenzaron a organizarse en Santiago. Los Amigos de la Vida fue una organización que en sus discusiones y debates comenzó a tomar un cariz ideológico y político mucho más marcado, lo que al ser detectado por las autoridades parroquiales resultó en su disolución, apartando del espacio a los miembros fundadores, reformulando y neutralizando el espacio (Luque, 2009). Expulsados de la parroquia y buscando espacios autónomos para organizarse, los refugiados peruanos comenzaron a estrechar más aún sus lazos con las organizaciones de izquierda y de Derechos Humanos. Nacen a partir de estos encuentros organizaciones sociales como la Asociación de Inmigrantes por la integración Latinoamericana (APILA) y el Comité de Refugiados Peruanos en Chile (CRP). Dos organizaciones de fuerte y larga presencia en la comuna de Santiago. Según una participante del CRP en aquellos años, los inicios de las organizaciones de refugiados estaban marcadas por las discusiones sobre la situación política del Perú, por las estrategias de reagrupamiento del movimiento popular peruano contra Fujimori y por la defensa de los derechos humanos de los refugiados peruanos frente a la violencia militar en su país (anónimo, entrevista personal, octubre 2018) ${ }^{1}$ Temas que actualizaron muchos de los conflictos partidistas que tenían en el Perú, siendo espacios constantemente tensionados internamente. Otro participante de esas organizaciones nos comenta que esa orientación les impidió vincularse socialmente a los migrantes peruanos que estaban llegando al país, enfrentando distintas experiencias de exclusión (anónimo, entrevista personal, diciembre 2017).

En efecto, este proceso, coincide con una tendencia marcada por el creciente arribo a las comunas pericentrales de Santiago de migrantes de tipo económico de países como Perú, Bolivia y Ecuador. Concentrándose poblacionalmente en comunas como Santiago, Recoleta, Independencia y Estación Central (Martínez, 2008), estas comunidades empiezan a tomar una visibilidad pública en base a ciertos prejuicios y estigmatizaciones que los medios de comunicación y algunos políticos comienzan a construir como representación sobre una "inmigración masiva" normalmente de peruanos "ilegales" que estarían ocupando los servicios públicos y copando las plazas de trabajo de los chilenos (Correa 2011; Doña 2002). Lo que se

\footnotetext{
${ }^{1}$ Los nombres de algunos entrevistados y los partidos de los que provenían en el Perú fueron anonimizados por su seguridad.
} 


\section{Bruno Rojas}

tradujo en una serie de formas de discriminación y xenofobia que se imponían en estos años sobre los migrantes de estos países. ${ }^{2}$

Frente a la indiferencia de los Estados chileno y peruano, la necesidad de insertarse socialmente este contexto fomentó los flujos de ayuda mutua, cuidado y acogida de las redes de migrantes. Éstas sirvieron como tejido social basal para la rearticulación de sus formas de sociabilidad y cultura. Esto queda patente en el relato que hacía Francisco Bazo e un escrito de la época, actual participante del Movimiento de Acción Migrante (MAM), de las primeras organizaciones de estas emergentes comunidades migrantes. "Inicialmente -afirmaba- pensaron que el migrar era un reto personal que, con el esfuerzo individual y el apoyo familiar", podrían alcanzar con éxito los objetivos que se plantearon al dejar el país. "Salvo los grupos de exiliados que se fueron organizando al poco tiempo de llegar para defender sus intereses, para el resto las primeras organizaciones fueron de carácter deportivas o para compartir el tiempo libre." Surgiendo primero "organizaciones asistenciales bajo el alero de la iglesia" mientras en el último período habrían "crecido la cantidad y diversidad de organizaciones de migrantes. Hoy existen organizaciones reivindicativas, culturales, deportivas, religiosas, gremiales..." (Bazo, 2004, p.4).

Refiriéndose a los problemas para insertarse socialmente, reiteraba que "estos problemas, unidos a las imágenes levantadas por los medios de comunicación que presentan al inmigrante andino como víctima o como un peligro para la sociedad receptora aumentan la vulnerabilidad del migrante e incrementan la tendencia a establecer getos" en ciertas zonas de la ciudad. (Bazo, 2004) Espacios de segregación de los que comenzaron a surgir estas comunidades y organizaciones sociales como respuestas tácticas de solidaridad y ayuda mutua, mediadas y conjugadas por sus prácticas culturales en que rearticularon sus identidades socioculturales, a partir de sus países de origen y las trayectorias migratorias. Emergen así una serie de asociaciones socioculturales (musicales, de danza, de folclor, en fin) y religiosas de peruanos, asociaciones de ecuatorianos, bolivianos y progresivamente de otras nacionalidades que, si bien eran bien rotativas e inestables, comenzaron incluso a "cambiar ciertos barrios", transformando a la ciudad en términos culturales, estético y políticos (anónimo, entrevista personal, octubre 2018). Con el desarrollo de estas redes y comunidades, las organizaciones de refugiados políticos comenzaron a vincularse y a trabajar los recién arribados. Ayudándoles con los procesos de regularización migratoria, siendo apoyados en su búsqueda laboral y en información de acceso a los servicios básicos, los refugiados, con más contactos y experiencia política, articularon "redes de inserción" y unidades asistenciales informales que se enmarcaron en una "cultura de la acogida e integración". De ese modo, las organizaciones de refugiados comenzaron a acoger contingentes de migrantes y paisanos a partir de los problemas y necesidades concretas que enfrentaba su gente (Luque, 2002a, pp. 75-76). Instalándose en la calle Catedral, en el Barrio Yungay o en la Plaza de Armas, estos grupos de exmilitantes se insertaron en las redes sociales de sus connacionales que estaban medrando por el centro de la ciudad a partir de la necesidad de insertarse a la sociedad chilena y las dificultades que sus trayectorias migratorias encontraban.

Organizaciones como el CRP y APILA, junto a nuevas organizaciones como la Asociación de Peruanos Residentes en Chile (ARPECH) operaron en barrios anclados

\footnotetext{
${ }^{2}$ Bazo registraba estos agravios denunciando que los "medios de comunicación hablaron de oleadas, de invasión y surgieron los fantasmas de la competencia desleal", desempleo, incidencia negativa en los salarios, saturación de los servicios públicos, particularmente en salud y educación. Afirmando que cuando "Chile recibe el impacto de la crisis asiática y se incrementan los índices de desempleo, alimentando las opiniones y comportamientos xenofóbicos y discriminadores que se desarrollaron en diversos sectores frente a los migrantes andinos" (2004, p.2).
} 


\section{Bruno Rojas}

territorialmente (Merklen 2010) realizando acciones para que los migrantes conozcan sus derechos, movilizando información que el Estado no comunicaba a las comunidades migrantes, levantando espacios de apoyo mutuo y reconocimiento (Luque, 2002b). Por otro lado, se configuran espacios como Proandes y el Colectivo Sin Fronteras (CSF), que trabajaron bajo el formato de ONG y corporación, realizando actividades investigativas, con acciones de intervención social y comunitaria a partir de la comunicación y promoción de los derechos hacia las comunidades, pese a que ambas tendieron a diferenciarse en su modo de inserción social y territorial.

Con el tiempo, vemos como algunas de estas organizaciones van excediendo sus labores de acogida, realizando acciones de interlocución y representación de las comunidades migrantes frente a otros actores sociales y políticos de la sociedad. Francisco Bazo caracterizaba esto como un proceso de desestigmatización e integración de las comunidades migrantes al país. Fundamental, porque había "permitido, crear espacios de acogida, canalizar las demandas, buscar soluciones a los problemas existentes, generar interlocutores válidos frente a los estados y la sociedad civil, servir de canales de información, relacionarse con los medios e instituciones chilenas" ayudando a contrarrestar las "imágenes negativas existentes y en definitiva aportar a la integración positiva en la sociedad receptora." (Bazo, 2004, p.4)

A partir de su participación en foros, en encuentros con otras organizaciones sociales, interlocución con políticos y una cierta instalación mediática, las y los dirigentes de estos espacios intentaron representar a los migrantes en la institucionalidad chilena, denunciando las necesidades de sus comunidades e intentando canalizar sus necesidades y problemas a nivel institucional (Jensen y Valdebenito, 2010).

Con la polémica pública que comienza a dibujarse en los medios frente a la supuesta oleada de peruanos y bolivianos que llegaban a Chile en medio de crecientes tasas de desempleo, el gobierno de Frei Ruiz-Tagle propuso el primer Plan de Regularización de los Inmigrantes "Irregulares" publicado como amnistía provisoria en octubre de 1998, la cual fue la única medida tomada por el gobierno en este periodo en materia migratoria (Freixas, 2018). Con ello, a cerca de 22 mil extranjeros se les otorgaron visas de trabajo temporales por dos años optando a su residencia temporaria sin la necesidad de un contrato de trabajo, requisito que operaba a partir del sistema de visación vigente como dispositivo reproductor de irregularidad migratoria. Pese a esta medida excepcional, ya para el año 2002 los datos del DEM estimaban que la cifra de extranjeros irregulares ascendía a entre 15.000 y 20.000 personas, lo que indicaba entre otras cosas lo ineficaz de la medida, así como lo sistémico del problema (Jensen, 2008). Luego de algunos años, frente al rápido aumento de la irregularidad y las violencias que esto traía para las comunidades migrantes, las organizaciones comenzaron a exigir un nuevo proceso de regularización a partir de una serie movilizaciones y acciones bajo la bandera de la Amnistía Migratoria.

\section{Trabajadores migrantes en la lucha por una amnistía migratoria}

Ante los problemas de regularidad y precarización laboral que viven trabajadoras de casa particular, y trabajadores peruanos de la construcción y de servicios comienza un proceso de organización y de movilizaciones en las que las organizaciones de migrantes logran vincularse a otros movimientos y actores políticos. El 2001 se funda el Sindicato Asamblea de Trabajadores Migrantes, que fue una organización de migrantes peruanos y ecuatorianos en Santiago que se 
movilizó más de una vez para protestar por los derechos de las trabajadoras de casa particular y junto al CRP, participaron en actividades solidarias con los migrantes peruanos que circulaban por la calle Catedral.

En el año 2004 estas organizaciones se movilizaron por una nueva regularización migratoria. Levantando un discurso en defensa de los derechos de los trabajadores migrantes, promoviendo la unidad y la protesta conjunta de trabajadores nacionales y extranjeros por sus derechos. Un dirigente del CRP hacía un llamado a la comunidad migrante a asistir a una asamblea en las afueras de la Catedral de Santiago, para organizarse contra las violencias y por la igualdad de derechos de los trabajadores migrantes y nacionales (Clavería, 2004). El 18 de abril del mismo año, el Sindicato junto al Comité y una serie de organizaciones de migrantes peruanos y colombianos realizaron una marcha para exigir una nueva amnistía migratoria que llegó a congregar 300 personas, luego de haber entregado una carta en La Moneda planteando una serie de demandas al gobierno de la Concertación. Estas demandas, según explicó en la prensa un dirigente del CRP, vinculaban la demanda por una nueva amnistía migratoria con la necesidad de acabar con la discriminación laboral y la xenofobia que afectaba a los "trabajadores migrantes", al poder regularizar su condición migratoria y poder integrarse a la sociedad chilena en igualdad (La Nación, 18 de abril, 2004).

En el Barrio Yungay, organizaciones culturales y territoriales chilenas se vincularon a las organizaciones y comunidades migrantes. Organizaciones territoriales como APILA buscaron comunicar la idea de integración y "convivencia armónica" entre chilenos y migrantes. Este tipo de esfuerzos hicieron que en diferentes centros culturales y agrupaciones folclóricas del barrio, medrara un discurso latinoamericanista que ha permeado la identidad del mismo, y que se ha expandido en sendos sectores de la juventud chilena que ha participado activamente en grupos de tinku, forró, cumbia peruana, bailes afroperuanos, salsa, etc., siendo protagonista junto a las comunidades migrantes de un proceso de transculturación que ha permeado comunas como Recoleta, Quilicura, Renca e Independencia. ${ }^{3}$

Paralelamente, en el centro de la ciudad los migrantes peruanos forman una organización de carácter eminentemente más político: Fuerza Inmigrante (FI). Conformada sobre todo por refugiados peruanos, sus participantes levantan la idea de un movimiento político que represente a las comunidades migrantes en términos electorales para instalar sus demandas dentro de la institucionalidad. Bajo la consigna “¡Los pueblos no tienen fronteras!”, el FI se anclaba socialmente a los migrantes de Santiago centro de extracción popular, buscando representarlos "más allá de la nacionalidad" particular. Congregado a sus paisanos fuera del local Punto Perú en calle Catedral, este espacio dinamizó la discusión política en las redes de sociabilidad e inserción migrante que nutrían el centro santiaguino en las casas de cambio, los almacenes peruanos, entre

\footnotetext{
${ }^{3}$ Patricia Loredo nos comentaba al respecto como las organizaciones culturales que nacieron primero "eran solo de migrantes haciendo cultura de sus comunidades y países de origen. Ahora no, la mayoría de las organizaciones son mixtas", habiendo "una transformación muy grande en las culturas juveniles." Lo cual había cambiado las formas en que se "configuran también su participación", diversificando los "significados que tienen los jóvenes" pues para muchos de ellos había "un componente que a través de esa organización hacen resistencia, una resistencia cultural al sistema, que es una forma de generar una tensión a los valores hegemónicos." Destacando las luchas tras tales espacios "de la cultura, del rescate, de legitimar que un chileno haga Caporal que es de Bolivia, con todas las tensiones que tiene Chile con Bolivia...tal vez no todos lo elaboran en su discurso como expresiones de resistencia" pero existía ese elemento. Participación que los iba sacando del mero consumo o de una vida solo dedicada al trabajo, comprometiéndose en un proceso de construcción de identidades, afirma Loredo, "por un lado más populares y por otro lado más latinoamericanistas” (Loredo, 2018).
} 


\section{Bruno Rojas}

vendedoras ambulantes, restaurantes y centros de llamado internacional, donde los migrantes rearticulaban su nueva cotidianidad urbana.

Durante el 2015, frente a varios casos de desalojo ejecutados por el gobierno municipal de Carolina Tohá, FI y sus comunidades se movilizaron denunciando la inhumanidad de las medidas, llamando a la "solidaridad del pueblo chileno con el pueblo inmigrante" apoyando a las familias desalojadas (Toro, 2015). En ese mismo sentido, también participaron de las manifestaciones de los trabajadores promoviendo y visibilizando los derechos de los y las trabajadoras inmigrantes (Noriega, 2015). En todas estas movilizaciones levantaron las demandas de la amnistía migratoria, el fin de la visa sujeta a contrato con el requisito de mantención del mismo empleador por dos años, comenzando progresivamente a exigir una nueva Ley de migraciones y la reforma constitucional para el reconocimiento de los niños apátridas (Comité de Refugiados Peruanos y Fuerza Inmigrante, 2014). Acciones colectivas que les permitieron vincularse a otras organizaciones sociales chilenas, así como vincularse a otros migrantes.

A partir del apoyo de FI y al alero del CRP, un grupo de trabajadoras de casa particular de diferentes nacionalidades levantaron un espacio de apoyo mutuo que las lleva a formar un sindicato que las defendiera frente a las experiencias de abuso que y abandono que estaban enfrentando (Lobos, 2017). Bajo el lema "Por un trabajo digno, no servil" el 22 de abril del 2012 estas trabajadoras forman el Sindicato Nacional Inter Empresa De Trabajadores Inmigrantes de Casa Particular (SINAINCAP), el cual se proyecta como un espacio autónomo políticamente desde el cual levantar sus demandas. En la declaración de su conformación, afirmaban la necesidad que tenían los trabajadores inmigrantes para organizarse, debido a que los "inmigrantes extranjeros tenemos demandas y necesidades especiales" a partir de la regularidad migratoria, la falta de previsión y los abusos e informalidad en el trabajo. "Reivindicaciones, necesidades y demandas que es deber de nuestro Sindicato plantearlas, ante los empleadores, ante las autoridades del país y ante las propias organizaciones amigas del pueblo para que la asuman como suya" (SINAINCAP, 2012a). Reuniéndose todos los domingos, único día libre para la mayoría de las socias del sindicato; estas madres y trabajadoras desarrollaron un proceso organizativo que rápidamente se transformó en un referente de las organizaciones migrantes en Santiago.

En un contexto donde trabajaban sin regulaciones laborales, con jornadas de trabajo extendidas indiscriminadamente, estigmatizadas y discriminadas, violentadas sexualmente muchas de ellas por sus patrones, el SINAINCAP ha posicionado un discurso de dignificación del trabajo doméstico y de cuidados, de reconocimiento social de su trabajo, promoviendo activamente los derechos ciudadanos y humanos de las mujeres trabajadoras migrantes. Como lo definía una de sus dirigentas era "un espacio para reunirnos y solidarizarnos. Un lugar de humanidad." (Figueroa Cornejo, 2014). Realizando talleres internos, almuerzos dominicales, charlas, foros y discusiones, estas trabajadoras se dieron espacios de esparcimiento, encuentro y formación en autonomía generando una dinámica que incentivaba la participación de las compañeras que iban sumándose al trabajo asociativo. Con talleres de baile y expresión oral, mejoraron su capacidad de hablar y conducir sus asambleas pudiendo abrir las discusiones al interior del espacio, democratizando la voz. Con ello, rápidamente empezaron a sacar sus primeras definiciones y lineamientos, participando de las luchas de las trabajadoras de casa particular para que Chile ratificara el Convenio de la OIT 178 en función de formalizar y regular la protección social y la jornada laboral. Objetivo ante el cual se movilizaron y mantuvieron reuniones con otras organizaciones del sindicalismo chileno para sensibilizar y comunicar las particularidades de sus necesidades como trabajadoras migrantes (Lobos, 2019, p.21) 
Enmarcaron sus demandas en tanto trabajadoras, mujeres y migrantes en una lucha contra la discriminación y por la igualdad de oportunidades con el pueblo chileno, llamando a las organizaciones populares a empatizar y a hacer suyas las demandas de las trabajadoras migrantes, avanzar junto en unidad. (SINAINCAP, 2012b)

Con las movilizaciones que sacuden a la sociedad desde el 2006, comienza un proceso de acción colectiva y contenciosa que parece crece en espiral (Ruiz, 2020): las huelgas de los trabajadores subcontratados (2007), el movimiento estudiantil (2011) y las movilizaciones medioambientales hasta las movilizaciones contra el sistema de pensiones (2016) y el movimiento feminista: en diferentes conflictos sociales comienzan a madurar procesos de descontento y de construcción de reivindicaciones y subjetividades cristalizando en movimientos sociales y organizaciones sociopolíticas, abriéndose una estructura de oportunidades políticas para diferentes reivindicaciones y demandas transformadoras del orden social de la transición. Dentro de ese marco, FI, el SINAINCAP y el CRP se hicieron parte de espacios como el comunal de Santiago de NO+AFP, participaron de las demandas estudiantiles y de las reivindicaciones del pueblo mapuche y compelidos por las compañeras de sus espacios, asistieron y participaron de las marchas de la coordinadora "Ni una menos" realizadas en el centro de la ciudad durante el 2016 y 2017.

A partir de esta apertura y la experiencia obtenida en estas luchas estas organizaciones de migrantes realizan un llamado a todas las nacionalidades del "pueblo inmigrante" a un nuevo ciclo de movilizaciones por la amnistía migratoria. Concentraciones y marchas que lograron expandirse a diferentes regiones de forma coordinada. Esfuerzo organizativo que dio pie en el 2014 a la creación de la "Coordinación por la Amnistía e Integración Migratoria", articulación que tuvo participación de comunidades migrantes y organizaciones de derechos humanos de Arica e Iquique, y que realizó una serie de movilizaciones que buscaron posicionar los derechos de los inmigrantes frente al despojo de derechos ciudadanos que la irregularidad migratoria proyecta sobre sus comunidades.

Sin embargo, este posicionamiento de su derecho a migrar e integrarse a la sociedad chilena, no enmarcaba sus demandas en una crítica al racismo como una matriz articulante de las jerarquías y exclusiones que viven las comunidades migrantes. Esto queda expuesto en las críticas instaladas en la prensa en sus movilizaciones o en sus publicaciones. En agosto del 2014 se realizó una movilización por una nueva amnistía migratoria en la que Fuerza Inmigrante hacía un llamado a la movilización por un nuevo proceso extraordinario de regulación. Afirmaban en un comunicado que la "idea es mostrar a las autoridades y a la opinión pública que ese planteamiento es necesario, es urgente y que beneficia tanto a la comunidad inmigrante como al país en su conjunto". Proponían para ello un "mecanismo especial" que permita de manera extraordinaria que los trabajadores inmigrantes puedan "regularizar su residencia, sin los límites o las sanciones, más de una vez desproporcionadas e inadecuadas, que impone como barreras la actual política y legislación en la materia”. Ello permitiría según su visión que los trabajadores inmigrantes "puedan tener una residencia para así trabajar y aportar en mejor forma al país, tanto para su bienestar como para el de la comunidad en conjunto, ello impidiendo situaciones de abuso, así como el ejercicio pleno de derechos." (Comité de Refugiados Peruanos en Chile y Fuerza Migrante, 2014). Movilizando una identidad como trabajadores que cumplen con los términos del "migrante permitido" (Zapata, 2019) en tanto aporte para el país y buenos trabajadores, estas agrupaciones instrumentalizaban este discurso para ser reconocidos como parte de los trabajadores y así legitimar sus demandas de reconocimiento legal y poder ser sujetos de derechos y dignidad. 


\section{Bruno Rojas}

En el nivel orgánico, estas movilizaciones empiezan a ampliar su marco territorial de influencia y estabilizarse en el tiempo logrando fundar la primera articulación de organizaciones de migrantes a escala nacional: la Coordinadora Nacional de Inmigrantes (CNIM). La primera orgánica con cierta capacidad de operar en la capital y en algunas regiones que se dio la tarea de representar las luchas por los derechos de los migrantes y coordinar diferentes organizaciones, campañas públicas, movilizaciones y actividades a nivel nacional, convirtiéndose en uno de los referentes más reconocidos en la lucha por los derechos de los inmigrantes en la actualidad. A todas luces esta cristalización es fruto de un proceso de aprendizaje y de diversificación de las organizaciones, sus roles y tareas, que crecieron con las movilizaciones por la amnistía migratoria y la lucha por el reconocimiento, pujando un proceso de diversificación y articulación de las redes entre migrantes compatriotas, incentivando la emergencia de nuevas organizaciones de migrantes. Paralelamente, en otras comunas y sectores de la ciudad, organizaciones conducidas por mujeres como el CSF, Warmipura, así como otras organizaciones sociales, llevaban años de trabajo, denunciado y elaborando propuestas mucho más concretas respecto a una nueva Ley migratoria con enfoque de derechos humanos, enmarcando sus demandas en una crítica mucho más profunda al racismo y la violencia que estaban viviendo sus comunidades, especialmente las mujeres y niños.

\section{Mujeres inmigrantes en lucha por los derechos humanos}

Una de las organizaciones pioneras en el trabajo de defensa de derechos humanos de los migrantes fue el Colectivo Sin fronteras. Nacido el año 2003 a partir de una fracción de mujeres refugiadas y profesionales que salieron del CRP para trabajar por la defensa de las infancias migrantes. Una de sus fundadoras, Ana Cortez, comentaba en una entrevista cómo los derechos de los niños y familias migrantes estaban siendo vulnerados impúdicamente por el Estado, destacando que se encontraban sin acceso a educación formal, con padres sujetos a duras condiciones económicas, con condiciones de habitabilidad precaria, sujetos al narcotráfico en las poblaciones, sin programas sociales que los reconocieran. Es frente a ese contexto que fundan el CSF (Cortés, 2008).

Instalándose en un cité en la comuna de Independencia, en la calle Barnechea del antiguo barrio La Chimba, las compañeras del colectivo comenzaron a trabajar con las comunidades del territorio por la promoción de derechos y la participación de las infancias y familias migrantes hasta la actualidad. Una de las lógicas de acción del CSF fue la denuncia y la incidencia en espacios de gobernanza en materia de migraciones, atendiendo "la falta de acceso a la salud y a las arbitrariedades administrativas que enfrentaban las mujeres sin residencia temporal o definitiva" al momento de asistir a un establecimiento de salud, así como "respecto a los impedimentos en el acceso a los establecimientos educacionales de las niñas y niños de familias migrantes en condición migratoria irregular" (P. Loredo, entrevista, 2017). Con ese objetivo, el CSF junto a otros actores de derechos humanos y espacios académicos, bregaron durante años para incidir en la creación de una normativa que permitiera la regularidad de las infancias migrantes, lo cual se logró mediante medidas administrativas de parte del Ministerio de Educación, quien normó la visación de los niños migrantes que estudiaran en colegios municipales (Cortés, 2008). Con todo, los niños en condición migratoria irregular no habrían podido acceder regularmente al sistema educativo municipal, pues muchas veces los oficios y 


\section{Bruno Rojas}

normativas administrativas referidas eran desconocidas en los colegios y no pocas veces no eran aplicados por discriminación de parte de funcionarios sin formación en materia de interculturalidad, en donde los malos tratos y los comentarios xenófobos eran vicios comunes $(\mathrm{P}$. Loredo, entrevista, 2018).

Más allá de esta agencia en espacios de gobernanza, sus participantes han sido críticas activas de las discusiones que se han dado en materia migratoria, de la institucionalidad y la gestión de las migraciones los diferentes gobiernos, a partir de los acuerdos internacionales que Chile ha firmado. En ese sentido, el CSF han aportado insumos y propuestas para una nueva institucionalidad de migraciones con enfoque de derechos humanos para los diferentes proyectos de Ley de Migraciones que se han levantado. Patricia Loredo comentaba en una entrevista, en cómo abogaban "porque esta nueva ley no solo venga a regular la vida de las personas extranjeras, sino también la ética, la moral, de la sociedad chilena". Pues solo en "la medida que se construya una sociedad inclusiva, donde no existan ciudadanos de primera y segunda clase, la sociedad chilena no tendrá problemas de cohesión, de fragmentación, de exclusión", que se han visto en otros países (Radio Uchile, 15 de enero 2017). De ese modo, han promovido en diferentes espacios una idea de ciudadanía más inclusiva, que integre una idea de interculturalidad y respeto a la diversidad, intentando instalarse y abrir nuevos espacios de participación e incidencia en seminarios, mesas de trabajo, espacios académicos y foros. Espacios de comunicación abiertos a la sociedad civil en los que han presentado críticas y propuestas concretas para trabajar la inclusión de las infancias y las familias migrantes.

Con una trayectoria así, sin embargo, el CSF no ha dejado su trabajo territorial y sus estrategias de intervención social comunitaria en la comuna de Independencia. Sin dejar el trabajo de incidir en la gobernanza migratoria, desde el colectivo siguen incentivando la participación y el empoderamiento de las comunidades con que trabajan en su territorio, especialmente de las niñas y niños que todos los días asisten a sus talleres, espacios de apoyo y actividades. Su trabajo comunitario enmarcado en la idea de la interculturalidad y el empoderamiento de sus comunidades, evocan la vocación transformadora de este espacio, ha buscado incentivar la organización de sus comunidades, cumpliendo funciones de red de apoyo para migrantes en condición de trata y en situaciones de violencia familiar o laboral contra mujeres migrantes. Del mismo modo como han implementado una serie de programas de acompañamiento social y legal a las familias migrantes que viven casos de desalojos de sus viviendas o que están en condición de vulnerabilidad (El Mercurio, 5 de febrero 2017).

A partir de una crítica explícita al racismo, el CSF ha buscado instalar sus demandas en las instituciones competentes, apoyar la organización de las comunidades migrantes de Independencia y Santiago y han desarrollado procesos educativos en base a los principios de la interculturalidad y con perspectiva de género. De ese modo han hecho del respeto a los derechos humanos de las niñas y niños migrantes y sus familias su proyecto político.

Otro caso de organización conducido por mujeres migrantes lo constituye Warmipura 4 . Espacio formado el 2005 para defender los derechos de las mujeres migrantes a partir de la iniciativa de un grupo de refugiadas y migrantes peruanas. Desarrollando investigación sobre las condiciones de las mujeres migrantes, levantando talleres sobre la violencia hacia las mujeres y apoyando y acompañando en casos de vulneración de derechos en nudos críticos como la violencia intrafamiliar y laboral, la salud de las comunidades migrantes, así como organizando protestas contra la especulación y el hacinamiento de los migrantes en los cités del centro

4 "Entre mujeres" en lengua quichua. 


\section{Bruno Rojas}

santiaguino. La dimensión territorial de su acción derivó progresivamente a labores de contención, apoyo mutuo y autoafirmación entre mujeres que perfilaron los rasgos comunitarios del espacio (Revista Sur, febrero 2013).

Por otro lado, Warmipura desarrolla una serie de vinculaciones con organizaciones sociales en la comuna de Recoleta. Vinculándose a juntas vecinales, escuelas comunales y una serie de organizaciones sociales afines. El 2011 formaron parte de una plataforma que articuló a organizaciones migrantes y promigrantes. La "Red de organizaciones por los y las Migrantes en Chile", que significó un importante primer esfuerzo por generar un frente común por los derechos humanos de los migrantes en la Región Metropolitana.

En un comunicado del 24 de agosto del 2011, Warmipura reflexionaba sobre los procesos de articulación y la lucha que estaban dando por visibilizar y terminar con la violencia hacia los migrantes y las mujeres. Afirmaban ahí la necesidad de "desentrañar los prejuicios sobre la Migración ya sea de la población migrante como de la población nacional, asimismo integrar a esta dinámica a la mujer nacional, que como tal, también es violentada, ampliando nuestro trabajo bajo una sola bandera: ¡Por Autonomía y Derechos Humanos de la Mujer!” De ese modo, mujeres inmigrantes y nacionales, que eran ambas víctimas de discriminación y violencia, "estamos trabajando porque esta sociedad que nos alberga conciba el fenómeno de la migración y la violencia en contra de mujeres como un fenómeno social, la misma que la entendemos como una responsabilidad colectiva" (Warmipura, 2011).

Las bases sociales que tuvo Warmipura, al constituirse sobre todo en base a trabajadoras de casa particular, le imprimió un carácter de género y popular a su organización y a sus demandas. Esto implicó no solo una problematización de la condición de exclusión de las comunidades migrantes, sino que puso en cuestión la violencia física, psicológica y sexual que constataron vivían las mujeres pobladoras e inmigrantes en la ciudad. Enmarcando su lucha en la idea de autonomía de las mujeres y una agenda pro derechos afirmaban la necesidad de "integración" de sus comunidades no a partir de ajustes solo institucionales, sino que mediante la organización popular (Sarzosa, 2009). Enfoque mediante el cual realizaron varios encuentros de mujeres inmigrantes y chilenas que las vincularon con otros referentes organizativos locales. Así, también participaron de movilizaciones contra la violencia hacia las mujeres y convocaron a organizaciones hermanas a tres encuentros de mujeres en los que definieron sus líneas de trabajo. En el segundo encuentro realizado el 25 de noviembre del 2012, algunas de las conclusiones más relevantes en materia de inmigración, género y discriminación, definían un diagnóstico y un proyecto a realizar. Afirmaban autocríticamente que aún no lograban una mayor incorporación de las mujeres a las distintas organizaciones territoriales y funcionales, pues: "Debemos reinventar formas para la incorporación y/o participación de las mujeres migrantes a las organizaciones tanto de la comunidad nacional como de la comunidad migrante (juntas vecinales, comités de vivienda, organizaciones culturales, etc)".

Ya que creían que las organizaciones "deben ser espacios de información, comunicación, acompañamiento y defensa de derechos; son los primeros instrumentos de los que se valen las mujeres" para tener el soporte y acompañamiento necesarios. "Debemos trabajar en red. Pero principalmente debemos vincularnos a las organizaciones territoriales de la comunidad chilena" para "poder transformar positivamente las relaciones con la comunidad destino y combatir así la discriminación y la xenofobia contra la población migrante" (Revista Sur, diciembre 2012).

Esa dimensión me parece relevante, porque postula el combate de la discriminación y la xenofobia hacia las y los migrantes a partir de la transformación de las relaciones de la comunidad política en general. Apuntando que el enfrentamiento de estas dinámicas de exclusión 


\section{Bruno Rojas}

debía afrontarse a partir de la acción en conjunto con las organizaciones chilenas. Elemento que se expresa de forma continua y va siendo discutido y repensado por las organizaciones de migrantes, así como los espacios y movimientos con los que se vinculan. A partir del asesinato del afrocolombiano Wilson Quintero el 12 de abril del 2012, el cual queda sin imputados y con poca visibilidad. Warmipura defendía que solo con la organización y la movilización se podía combatir desde sus espacios "el racismo y toda forma de discriminación e intolerancia." (Warmipura, 2012) Apuntando la necesidad de ponerle un alto "a esta situación, no estamos solas en esto, y por ello es importante generar corrientes de opinión para detener los abusos, la discriminación" así como "la xenofobia (odio contra los extranjeros)" en los colegios y en los centros de trabajo. En el mismo documento terminaban diciendo, que "si hay una respuesta organizada frente a la intolerancia, incidiríamos en la forma de pensar de las personas" (Warmipura, 2012). En definitiva, el enfrentamiento del racismo a través la organización y el cambio social dejaba de manifiesto para ellas que esta opresión no sólo operaba a nivel de las instituciones o en experiencias cotidianas de discriminación, sino que relevan la dimensión social y cultural de esta experiencia, razón por la cual se le podía hacer frente mediante la acción colectiva con fines a influir en el comportamiento social más general.

Creo en ese sentido que la táctica de organizarse y aliarse con organizaciones locales para poder juntos enfrentar el racismo, busca enmarcar las demandas migrantes como una lucha en común que implica el reconocimiento mutuo entre chilenos y las comunidades migrantes. Creo que esa lucha desde y por el reconocimiento, que excede el reconocimiento legal y que busca terminar con sus experiencias de menosprecio social (Honneth, 2011), es la que comienza a ser significada en las consignas y cánticos que he observado en mi trabajo de campo en las movilizaciones migrantes. "¡Los migrantes, no somos delincuentes, somos trabajadores internacionales!" "¡Migrar, luchar, nadie es ilegal!” “iLa migración es un derecho y no un delito!" "CChilena o extranjera, la misma clase obrera!” Es por esto que creo que las organizaciones de migrantes han buscado proyectar políticamente una defensa de los derechos humanos que tensiona a un cierto discurso multiculturalista atrincherado en la exaltación mercantil de la diferencia, instalando sus demandas por reconocimiento en el marco de una lucha más general junto al pueblo chileno y sus organizaciones, en una lucha por la dignidad común.

\section{Las articulaciones nacionales y la reivindicación antirracista}

A partir del año 2016, emergentes flujos migratorios comienzan a consolidarse y a cambiar los marcos de la pluralidad cultural de la sociedad chilena. Frente al robustecimiento de los sistemas de control fronterizo y a las políticas migratorias con enfoque securitario en los países históricamente consolidados como destinos de la inmigración caribeña (EU, Europa, etc.), emigrantes de países como Haití y República Dominicana comienzan a arribar a países relativamente estables en el panorama latinoamericano como Brasil y Chile. A lo cual desde el 2016 ha seguido un ciclo de inmigración venezolana en medio de la crisis política y económica que ha enfrentado ese país. En Chile, esta nueva fase del ciclo migratorio, caracterizada por su componente afrodescendiente y su concentración territorial en algunas comunas de Santiago como Quilicura, Estación Central, Independencia, Recoleta, y Huechuraba-, Antofagasta y Arica, ha sido representada en los medios de comunicación de formas estigmatizantes, sedimentando maneras de comprender y concebir al "Otro" migrante con imágenes asociadas a la delincuencia, 


\section{Bruno Rojas}

a la falta de higiene, a la sexualización, en fin, representaciones que han impregnado los imaginarios sociales (Rizik, 2019; Poó). Fundándose en ello un régimen de visibilidad que afirma la presencia de las migraciones en la ciudad como excesiva, lo que ha acrecentado los discursos y las orientaciones racistas presentes en la sociedad chilena.

En este contexto de aumento de los flujos, las redes de entre migrantes crecen y van desplegando diferentes estrategias de inserción social, mientras el problema de las condiciones de desprotección y la vulneración de los derechos de los migrantes empieza a tomar ribetes cada vez más dramáticos. Es por eso que comienzan a surgir nuevas organizaciones que se involucran en la defensa de los derechos humanos de los migrantes a partir de lo cual comienzan nuevos procesos de articulación a mayor escala. A partir del trabajo en la Reunión de organizaciones migrantes en la R.M, Warmipura y otras organizaciones como la Organización Socio Cultural de los Haitianos en Chile (OSCHEC), la Asociación de Uruguayos en Chile y el Colectivo Ecuatoriano por la Ciudadanía, comienzan a levantar un trabajo en conjunto en materia de legislación migratoria con enfoque de derechos humanos. A partir de su trabajo en conjunto en la Mesa Temática de Migración ${ }^{5}$, estas organizaciones deciden formar un espacio autónomo de reflexión e incidencia social que les permita trabajar con otros actores, a partir de lo cual fundan el Movimiento de Acción Migrante (MAM). Unidos por el trabajo por los derechos humanos con sus comunidades, este espacio surge con la visión de construir un movimiento que permitiera articular a las diferentes organizaciones de migrantes y poder comunicar y politizar sus demandas (Albuja, 2014). Buscando el reconocimiento estatal de los derechos de los migrantes, así como promoviendo la organización y participación de las comunidades, el MAM ha operado explícitamente como un agente con una fuerte labor comunicativa e informativa en materia de derechos, generando redes de apoyo y promoviendo diferentes iniciativas desde la sociedad civil (Morales, 2016) como ayudas en casos de trata de personas y en desalojos de campamentos. Para lo cual se ha vinculado estrechamente al campo de las organizaciones sociales y populares, y con los partidos con agendas promigrantes como los perteneciente al Frente Amplio (FA) y al PC. Junto a los cuales ha intentado incidir en espacios de gobernanza y con parlamentarios en la formulación de políticas públicas en materia de migración y discriminación.

El 2014 el MAM se hace parte del Consejo Consultivo de Migraciones. Espacio en el bregaron por integrar a la discusión sobre la institucionalidad migratoria el principio de reunificación familiar, el principio de igualdad de las personas en movilidad y la implementación del sistema de visa de uso múltiple (El Desconcierto, 2 de diciembre 2016). Medidas que buscaban reducir la burocratización sobre las trayectorias migratorias, el acceso a la información para los migrantes y la institucionalización de un enfoque de derechos (MAM, 2018).

El marco reivindicativo de sus propuestas se basa en el enfoque de Derechos Humanos, a partir de la idea de igualdad entre los seres humanos y la búsqueda de la interculturalidad entre los habitantes del país, se ha buscado poner fin a la violencia y la discriminación cotidiana hacia los migrantes. Realizando campañas mediáticas como "Mi piel, tu piel, Mi corazón, tu corazón. Vivamos en Paz" en la cual participaron artistas, intelectuales, pobladoras y trabajadores (El Ciudadano, 8 de julio 2017), el MAM ha buscado enfrentar el racismo y la discriminación retomando la categoría de su pertenencia común a la humanidad para legitimar sus demandas. Tal versatilidad y una capacidad cada vez mayor de instalarse mediáticamente, han hecho del MAM

\footnotetext{
${ }^{5}$ Espacio de gobernanza para retroalimentar la gestión parlamentaria en la que participaban académicos, políticos y organizaciones de la sociedad civil vinculadas a la migración
} 


\section{Bruno Rojas}

una de las organizaciones más visibles en la prensa y en los foros sobre migraciones, sin dejar estrategias de acción colectiva y distintas formas de movilizaciones.

Esto quedó muy patente el último año de gobierno de Michele Bachelet (2017), cuando el ingreso del anteproyecto de Ley que había sido trabajado con las organizaciones de emigrantes fue reiteradamente retrasado (Emol, 20 de febrero 2018). Lo que comenzó un tira y afloja entre oposición y gobierno, que termina por dejar de lado el trabajo con las organizaciones, mientras el proyecto comienza a avanzar sin las propuestas que las organizaciones habían aportado al Consejo. El MAM y otras organizaciones de migrantes llaman a movilizarse afirmando que la Ley que sería presentada por el Ministerio del Interior no contenía la visión de los migrantes, increpando a las autoridades a permitir la participación en instancias resolutivas (Diario Uchile, 20 de agosto 2017). Refiriéndose a estos hechos, en una de estas marchas por una nueva ley migratoria, el MAM difundió una declaración interpelando la instrumentalización electoral que se estaba haciendo a partir de los migrantes y su legislación. Considerando que era una muy mala señal que un tema que tiene décadas de atraso y tanta importancia "aparezca justamente en periodo prelectoral, con una interpelación que seguramente se explotará para ganar la carrera por los votos. Mientras, nosotros no olvidamos que cuando todos los actores políticos decisores tuvieron herramientas y la potestad para actuar, no lo hicieron". El MAM era categórico en su evaluación de la política del gobierno, que expresaba "el nulo deseo que las organizaciones de la sociedad civil tengamos injerencia en el proyecto de ley ni menos opinión” (MAM, 2017).

Buscando coordinar una organización nacional, el MAM tuvo una relevancia importante en la conformación de la Red Nacional de Organizaciones Migrantes y Promigrantes ${ }^{6}$ que en marzo del 2017 tuvo su primer encuentro en Valparaíso. Red asociativa que se extiende por ciudades como Antofagasta, Temuco, Santiago, Valparaíso, Valdivia, y que emerge como una plataforma de articulación de las diferentes luchas que estaban llevando las organizaciones migrantes y promigrantes a nivel local y regional, con el fin de levantar demandas comunes y propuestas concretas en materia de legislación migratoria, discriminación e interculturalidad. Las organizaciones que conforman las $\operatorname{Red}^{7}$ han buscado convertirse en un actor con capacidad de operar en todo el país y que, más acá de representar a las comunidades de migrantes, permita una interlocución legítima desde la sociedad civil para presentar propuestas, denunciar y organizar soluciones y políticas públicas para los problemas de las comunidades migrantes, en la perspectiva de avanzar hacia una sociedad donde se reconozcan la justicia social y la dignidad de todas las personas por igual. La Red ha enmarcado su coordinación en un horizonte político de transformar la sociedad hasta que se reconozcan y garanticen los derechos de las comunidades, para lo cual ha promovido la organización y participación de éstas, enmarcando su accionar en la idea de una sociedad libre de discriminación de raza, clase, género, religión, sexo, y postura política (Red, ver en Tapia y Concha, 2018).

\footnotetext{
${ }^{6}$ En adelante, la Red.

${ }^{7}$ Las organizaciones que conformaban la red hasta el año 2018, eran el Movimiento de Acción Migrante, la Mesa Intercultural de Antofagasta, Asamblea Abierta de Migrantes y Promigrantes de Tarapacá, el Colectivo Sin Fronteras, Fractal, Agrupación Macrocampamento Los Arenales "Rompiendo Barreras", Asociación de Uruguayos en Chile, el Consejo Consultivo de Uruguayos, el Colectivo Ecuatoriano por la Ciudadanía, Colectivo Justicia para Guatemala, OSCHEC, Warmipura, Peruanos residentes en Santiago, Agrupación Miranda de Antofagasta, Colectividad de Colombianos residentes en Antofagasta, Centro social y cultural república de Ecuador, Congregación el Buen Pastor, Colectivo GRAM, el Movimiento de Poabladoras/es Vivienda Digna, entre otras.
} 


\section{Bruno Rojas}

Operando hasta la actualidad la Red se ha trasformado no solo en un actor que ha criticado las actitudes racistas de políticos o las discriminaciones institucionales que viven las comunidades, sino que se ha transformado en una plataforma de encuentro entre organizaciones migrantes y una serie de organizaciones populares. Algunas de las actividades que han realizado en ese sentido han permitido la participación de sus miembros en asambleas populares, vincularse con campamentos, escuelas y sindicatos, instalando en esos espacios ideas críticas con respecto a la criminalización de las comunidades migrantes, aportando con insumos respecto a una ley migratoria con enfoque de derechos o levantando espacios de discusión y acción contra el racismo a nivel local y nacional.

Así lo hicieron de hecho cuando denunciaron a la reforma migratoria de Bachelet como "Ley racista" por darle continuidad al carácter securitario de la legislación en un encuentro en Antofagasta en donde participaron dirigentes sociales, corporaciones y organizaciones locales (Revista Sur, 10 de octubre 2017). Sus elaboraciones han aportado materiales, datos y diagnósticos participativos con propuestas para una nueva legislación migratoria con enfoque de derechos humanos y han incentivado la participación y la organización de las comunidades migrantes junto a las organizaciones sociales locales, articulando redes de apoyo para casos de trata, desalojos de campamentos e incendios de cités. Por último, destaco también la acción comunicacional que han tenido para incidir en las ideas e imaginarios de la sociedad chilena, promoviendo campañas mediáticas, encuentros ciudadanos (Revista Sur, marzo 2018), han participado de cátedras libres, se han hecho parte de la Cátedra de Racismos y migraciones de la Universidad de Chile y han instalado mediáticamente su discurso de una "convivencia intercultural y la inclusión con justicia y dignidad" (Radio Uchile, 17 de marzo 2017).

A partir de sus discusiones, vemos que la búsqueda por la integración de los migrantes o la reivindicación por una sociedad sin violencia se enmarca en un horizonte normativo basado en la idea de la vida digna y el reconocimiento de la humanidad de todos sin importar color de piel o nacionalidad. Eso explica la participación de sus organizaciones en las movilizaciones feministas o en los comunales No + AFP, donde han podido comunicar la situación y las demandas de las comunidades. Por eso las organizaciones de migrantes si bien han mantenido su trabajo con las comunidades y los recién arribados, se han vinculado fuertemente a las organizaciones y movimientos sociales locales. Acción en la cual han podido integrarse y hacerse parte de otros conflictos. De ahí el carácter universalista de algunas de sus consignas como "Contra todas las violencias" o "La humanidad somos todos".

El SINAINCAP junto al CSF y sus comunidades se han hecho parte de este proceso en su vinculación con el movimiento feminista. Ya habiendo trabajado con el colectivo político feminista libertario La Alzada durante el 2015, la vinculación entre feminismo y migración derivó en la participación del SINAINCAP en espacios de discusión y lucha con la Coordinadora 8M (Radio Uchile, 2018) y en su participación del espacio de organizaciones de mujeres antirracistas, la Coordinadora 30 de septiembre, fundado al calor de lo que significó la muerte de Joan Florvil.

La muerte de Joan se articuló como un hito que abrió un nuevo periodo de articulación de las organizaciones de migrantes con los movimientos sociales, a partir de la visibilidad pública que alcanzaron los hechos de negligencias y discriminaciones que llevaron a la muerte de esta mujer haitiana, lo cual fue sindicado como efecto de la violencia institucional y patriarcal presente en la sociedad chilena. Para una dirigenta de estas organizaciones, a partir de este trágico hecho, las organizaciones sociales pudieron comprender de qué "estábamos hablando cuando hablábamos del racismo, qué podía significar esto en la vida de una persona" y que 


\section{Bruno Rojas}

permanentemente "las organizaciones denunciábamos, entonces que haya sido una situación tan trágica, que no sólo haya afectado a una mujer (...) humanizó el relato, se pudo dimensionar todas las implicancias de este relato y generar mucha identificación en el caso de las organizaciones populares que en lo cotidiano viven en conjunto la violencia." Identificación que permitió articular nuevos espacios y donde se empiezan a visibilizar los vínculos entre la lucha feminista y un emergente antirracismo (Loredo, entrevista personal, 2018). Estos vínculos toman forma clara cuando a inicios del 2018, la dirigenta histórica del CSF, Patricia Loredo, fue elegida como una de las voceras de la Coordinadora $8 \mathrm{M}$ para la marcha anual por el día de la mujer trabajadora, en representación de las mujeres migrantes organizadas en las luchas proderechos. En una entrevista, la nueva vocera reflexionaba sobre el proceso ocurrido este último año y el escenario en que se ubica esta nueva movilización feminista frente a los recientes hechos de violencia racista.

Durante ese año, desde la coordinadora, se ha generado un proceso de mayor articulación, tal vez, de organizaciones feministas con organizaciones sociales -como las del mundo sindical- que trabajan por construir una sociedad igualitaria. Y en ese sentido, creo que es mucho más esperanzadora la proyección de este trabajo por el derecho de las mujeres [...] pero en el caso de la migración y las mujeres migrantes la situación ha empeorado muchísimo. Nadie que vive en Chile -y esto también es parte de un contexto mundial- puede desconocer que el racismo se ha incrementado. Ya no solo se hace veladamente, sino que hay un racismo totalmente develado y amenazante que muchas veces ha generado situaciones ya no solo de violencia verbal, sino que también física: hacia trabajadores migrantes, a mujeres que les ha costado la vida, mujeres afrodescendientes, mujeres indígenas, mujeres migrantes. Especialmente en el tema de migración, creemos que hay un retroceso importante desde la sociedad chilena y el Estado [...] Lamentablemente creo que este gobierno saliente perdió la oportunidad de poder frenar esta alza racista en Chile, de construir un país más inclusivo y garantista de la dignidad de las personas que vivimos aquí. Y sobre el contexto que se viene, obviamente va a ser más complejo, y por eso estamos justamente fortaleciendo la articulación con los distintos movimientos sociales en una lucha más abierta, porque sin esta movilización nada va a avanzar. (El Desconcierto, 8 marzo 2018)

Ante esta creciente violencia racista, las organizaciones de migrantes que ya venían vinculadas a otros movimientos sociales se articulan con el movimiento feminista, y retoman la gramática de las luchas por la igualdad, la inclusión y la dignidad, aportando al entramado de reivindicaciones su denuncia del racismo, demanda que ha sido trabajada desde otro punto de vista por el movimiento mapuche, pero que con la amplitud del movimiento feminista adquiere otra dimensión.

La articulación del movimiento feminista con las organizaciones y demandas migrantes, si bien no ha estado exenta de tensiones y acalorados debates internos, ha dado un nuevo contenido a sus reivindicaciones en un esfuerzo al que se ha abocado un sector del movimiento feminista para desarrollar la "interseccionalidad de la lucha feminista" e integrar a las mujeres migrantes, indígenas y afrodescendientes (Loredo, 2018). Interacción que ha servido para una apropiación de parte de los movimientos sociales del proyecto de defensa de derechos y la protección de la dignidad humana que habían levantado las orgánicas de migrantes y por tanto una reelaboración de sus marcos. Antes que un proceso de ruptura, la emergencia de esta reivindicación antirracista 


\section{Bruno Rojas}

se ancla en la crítica a la xenofobia y la discriminación que había sido denunciada por las organizaciones durante años pero que en el reconocimiento mutuo entre movimiento feminista y las luchas migrantes, pasa adquirir una nueva centralidad, volviéndose hasta cierto punto un marco explicativo de las violencias que enfrentan las comunidades migrantes así como un horizonte de luchas contra el entramado de poderes que el racismo viabiliza y sostiene. En definitiva, a partir del 2017 comienza una creciente visibilización y la emergencia pública de una reivindicación antirracista. Marcada por la vinculación de las organizaciones de migrantes con los grandes movimientos sociopolíticos que definen el periodo pre-octubre, como es el movimiento feminista, el movimiento estudiantil y el movimiento NO+AFP, del mismo modo en que en las bases se han articulado redes con asambleas, sindicatos, campamentos y movimientos de pobladores. Así, se comienzan a desarrollar formas de articulación en múltiples niveles y formas entre diferentes reivindicaciones y organizaciones perfilando una especie de "interseccionalidad de las luchas" que era propuesta por Angela Davis como uno de los objetivos estratégicos para enfrentar las formas actuales de la dominación (Davis, 2018).

Es importante destacar, que el desarrollo de este proceso se dio en un contexto en el que las comunidades migrantes comenzaron a enfrentar una nueva ofensiva con la campaña mediática y política de parte de las fuerzas de derecha y los medios hegemónicos en la coyuntura electoral del 2017. Donde se estableció la idea del desorden migratorio ante el alza de los flujos, y la llegada excesiva de delincuentes (Acevedo et al; Rizik, 2019). Proceso que se institucionalizó en un enfoque de control y seguridad con el gobierno de Chile Vamos, que sistematizó este enfoque con paquetazo de políticas discriminatorias, como la exigencia de visas consulares para los migrantes haitianos, la eliminación del Consejo Consultivo de Migraciones, la imposibilidad de modificar la situación migratoria al interior del país y el retroceso en las garantías de un debido proceso para las expulsiones y el resguardo de derechos (Riobó et al, 2019).

El entrante gobierno estrena su política migratoria con un decreto administrativo con el que se exigió una visa consular específica para la población haitiana migrante en el país. Políticas que ya habían sido aplicadas a los migrantes dominicanos el 2012 que habían derivado en un fomento de la irregularidad migratoria poniendo en riesgo la vida de estas familias trabajadoras (Vargas, 2018). En ese mismo sentido el gobierno aplicó el Plan de retorno Humanitario, medida administrativa consistente que disponía una serie de vuelos de la FACh para regresar a Haití a los migrantes que lo necesitaran, bajo la cláusula de no regresar al país durante 9 años. Invocando un discurso humanitario, el gobierno defendió esta medida como un mecanismo opcional que tendría su fundamento en el respeto hacia los derechos humanos frente a los problemas económicos que estaría enfrentando esta comunidad como inmigrantes en el país (Radio Uchile, 2018). Sin embargo, la medida ocultaba una serie aspectos racistas que fueron denunciadas por una novedosa articulación de organizaciones haitiana, la Plataforma Nacional de Organizaciones Haitianas PLANOHCH. La Cual, frente a las supuestas razones humanitarias que motivarían el 'Plan de Retorno', afirmaban que estas se desvanecerían en contradicciones cuando se niega a los inmigrantes el derecho "a procurarse su subsistencia, cuando se nos prohíbe trabajar, cuando se exigen documentos innecesarios para realizar los trámites, cuando se prolonga indefinidamente y de manera absurda los trámites para mantenernos en una situación de eterna semi-regularidad migratoria" por lo que exigían un "proceso de regularización que en forma realista nos permita acceder a tener una residencia en el país" (El Desconcierto, 2018).

Frente a todas estas medidas, el MAM y la CNIM lograron consensuar un documento en el cual se criticaba la nueva política migratoria del gobierno por "la mirada utilitarista y economicista que manifiesta el Estado con relación a la migración." Alegando que la migración 


\section{Bruno Rojas}

era una "cuestión de derechos humanos y no un fenómeno que se controla de acuerdo con las necesidades o intereses de un Estado." Exaltando la necesidad de seguir trabajando e institucionalizar una legislación en "migración con enfoque de derechos (...) Creemos profundamente en que todos merecemos la misma dignidad no por nuestra nacionalidad, sino por ser humanos (MAM, 9 de abril, 2018).

Es a partir de estos agravios que la Coordinadora 30 de septiembre, el MAM, la Red, Warmipura Entre Mujeres, el colectivo antifascista Rash Sharp, Londres 38, el Movimiento de pobladoras/es Vivienda Digna, el Movimiento contra la Tortura Sebastián Acevedo, la Mesa Sindical de migraciones, la Plataforma de Organizaciones Haitianas y una serie de organizaciones migrantes y otras promigrantes comienzan un proceso de discusión y reflexión con el fin de trasnversalizar las demandas por los derechos humanos, la lucha contra el racismo y la violencia hacia las mujeres, convergencia que los lleva a constituir una plataforma que permita la politización organizada de esas reivindicaciones. Con el advenimiento del primer aniversario de la muerte de Joane, se autoconvocaron "contra la violencia institucional" promovida por el Estado chileno, levantando así la "Articulación de organizaciones migrantes y chilenas por los derechos humanos en Chile", espacio que reflexivamente se sobrepone a las políticas migratorias del gobierno y decidió buscar mecanismos de incidencia para visibilizar las violaciones a los derechos humanos y la violencia institucional. A partir de esa apuesta, el 30 de septiembre de ese año, día de la muerte de Joan, es convocada una movilización para el que llamaron "Día Nacional contra el racismo" (El Desconcierto, 26 septiembre 2018). Marchando más de mil personas desde avenida Recoleta hasta Cementerios, participan de la movilización más de 80 organizaciones sociales, incluyendo organizaciones vinculadas a movimientos sociales (C8M y No+AFP) y algunos partidos del Frente Amplio (Movimiento Autonomista y Revolución Democrática). Levantando la bandera de la "justicia y verdad" para Joane, el fin del racismo y la violencia institucional contra las diferentes comunidades violentadas y deshumanizadas por su condición de clase, de raza y de género, la movilización terminó con discursos de algunos voceros de las organizaciones de migrantes, pobladores y profesores. Así, en su declaración que fue leída al final de dicha movilización, se expresaba

La deshumanización que observamos tras estos hechos se ancla en la indiferencia de la sociedad y en el racismo de un Estado que nada hace por reconocer la dignidad y la humanidad de las personas migrantes que han llegado a trabajar a Chile. Un sistema de clasificación de las personas establece diferencias perversas para deshumanizar y es altamente peligroso al dar rienda suelta a los actos como los que hoy recordamos, lamentamos y denunciamos. A pesar de tan adverso escenario, encontramos quienes se rebelan ante esto en poblaciones, en las juntas de vecinos, en los sindicatos, en federaciones de estudiantes, en barrios y tomas, en los comités de vivienda de los pobladores, en las organizaciones de derechos humanos, en la cultura y en muchos otros espacios. De forma casi molecular se avanza en exigir que nadie sea privado de sus derechos, que se respete la dignidad de las personas y se haga justicia ante la violencia institucional e individual. El carácter integral de los derechos humanos exige que no callemos ante los atropellos que se pretende silenciar; pues haya sido ayer, o sea hoy o mañana, sea contra quien sea: mujer, hombre, niños(as), tenga la nacionalidad, el color de piel o el género que tenga. Esa humanidad tan necesaria la queremos construida entre todas y todos en una lucha constante. Es por todo esto que llamamos a la sociedad civil, a los movimientos feministas, estudiantes, a las organizaciones sociales, a las 
asociaciones de DDHH, a los sindicatos y los organismos de defensa de la infancia y de las mujeres, a los profesionales, funcionarios y trabajadores, a todas y todos, a solidarizar con las víctimas y a exigir la verdad y la justicia que merecen. (Revista SUR, septiembre 2018)

Surge así una articulación de organizaciones populares y políticas que encarna la reivindicación antirracista. Se abre así un camino que aún hoy sigue cultivándose con el esfuerzo ya no solo de las organizaciones de migrantes, sino que junto a diversos actores que buscan construir una fuerza social que puje por los derechos humanos, el reconocimiento social y ciudadano hacia las comunidades migrantes y por el derecho a una vida libre de violencia racista. Como dijo ese día Eduardo Carroza uno de los voceros de la Red "El llamado es a que cesen estas violencias institucionales que se expresaron en el caso de Joane, que prolifere la empatía, la comprensión y la solidaridad, porque queremos que este país crezca con todas y todos" (El Mostrador, 26 septiembre 2018). Bajo esos principios y valores, la reivindicación antirracista se está aún hoy difundiendo y relaborando prácticamente, lejos de la visibilidad pública, en asambleas y encuentros locales, en redes y grupos, es los trabajos y en los barrios populares, en carnavales y colectivos culturales juveniles, así como en convergencias políticas y movimientos. En aquellas heterotopías de la ciudad neoliberal emerge así un antirracismo migrante.

\section{Reflexión final}

El recorrido sociohistórico que he intentado trazar aquí se ha circunscrito específicamente a lo que he considerado como la agencia colectiva y los marcos reivindicativos de las organizaciones de migrantes.

La hipótesis que sustenta este trabajo es que para estudiar los procesos de exclusión y de inserción de la migración en la ciudad de Santiago, es necesario romper la frontera teórica que los estudios migratorios han introducido a partir de un concepto de racismo basado en una concepción radical de diferencia, que no permite la interacción y el reconocimiento entre la sociedad chilena y sus nuevos habitantes, impidiendo el análisis y la descripción de la politización colectiva de sus experiencias y reivindicaciones. Es por esto que en este artículo exploramos las organizaciones de migrantes, su despliegue práctico y sus reivindicaciones para analizar la capacidad de agencia de los movimientos migratorios, así como su interacción con la sociedad, en especial con el campo de las organizaciones y movimientos sociales.

Hemos señalado que a partir del giro de organizaciones de refugiados militantes a organizaciones migrantes se dio bajo modalidades orgánicas que van diversificándose desde las organizaciones locales y territoriales, hasta los espacios de construcción de bases comunitarias mientras van complejizándose hasta la emergencia de articulaciones y coordinaciones nacionales. Proceso organizativo en que las organizaciones de migrantes comienzan a convertirse en interlocutores de las comunidades, politizando los procesos de inserción y apoyo mutuo de las comunidades logrando articular una lucha por el reconocimiento que tensiona los marcos de la ciudadanía basada en la nacionalidad.

A partir de este marco general es que observamos tres dinámicas organizativas y reivindicativas. Por un lado, están las luchas de los migrantes que en tanto trabajadores bregan por su reconocimiento legal y su regularidad migratoria, a partir de las movilizaciones por la 


\section{Bruno Rojas}

amnistía migratoria, construyendo acciones comunitarias, formando redes de apoyo y asesoría. Por otro lado, se levantan organizaciones y colectivos de mujeres migrantes que comienzan a anclarse territorialmente y trabajar con las comunidades para fomentar su participación y su organización, apoyando a las familias y mujeres más desprotegidas, levantando demandas a fin de garantizar la igualdad de género, la protección a las infancias populares y una institucionalidad migratoria con enfoque de derechos humanos. Por último, se logran articular organizaciones con alcance regional y nacional, que realizan una serie de acciones comunicativas, acciones de gobernanza e incidencia y movilizaciones cada vez mayores en donde han buscado instalar en la esfera pública sus demandas, como han sido terminar con la discriminación y el racismo, y con una institucionalidad estatal que reconozca e implemente los derechos humanos para toda la población tensionando los límites del concepto de ciudadanía tradicional. En particular dentro de estas organizaciones, la relación entre las organizaciones de migrantes y el movimiento feminista, han permitido expandir el alcance de estas demandas y un reconocimiento cada vez mayor de parte de las organizaciones sociales locales respecto a las necesidades y proyectos de los migrantes organizados.

A partir de este balance histórico, quiero caracterizar este proceso organizativo de los migrantes y sus diferentes expresiones reivindicativas a partir del rol que han tenido en la democratización de la sociedad chilena. Esto, porque sus demandas y movilizaciones buscan ampliar los marcos del respeto a los derechos humanos en el país. Que estos sean reconocidos e implementados por el Estado, garantizados por el conjunto de las instituciones y que afecten realmente a la vida de todas y todos quienes habitan y trabajan en el territorio más allá de la nacionalidad y el color de piel. De este modo, los marcos en el que el Estado-nación los reconoce como parte de la comunidad política.

Por último, destaco la emergencia de un marco reivindicativo antirracista, un hecho al cual me dediqué a seguirle la pista, en particular, porque creo que reside en ese proceso de maduración política una serie de potencialidades filosóficas y políticas para las luchas transformadoras que están en curso, y que más allá de recientes excepciones (Pérez, 2019), han sido poco relevadas por la producción y elaboración de las ciencias sociales en el campo de los estudios migratorios así como en los estudios sobre acción colectiva y movimientos sociales. Por eso afirmo que desde los proyectos críticos con la discriminación que levantaron espacios como el CSF, APILA o Warmipura existe una línea de continuidad, trascendencia y complejización que tiene su expresión más notoria en la lucha antirracista que están levantando espacios como el MAM, la CNIM o la Articulación de Organizaciones Migrantes y Chilenas por los Derechos Humanos en Chile. Proceso sociopolítico que ha adquirido visibilidad publica en una serie de movilizaciones, y que incluso tomó forma en la inédita candidatura migrante de Manuel Hidalgo a la Convención Constituyente. Ya en el cierre de este estudio, en la marcha del Día Nacional contra el racismo, esta reivindicación antirracista demostraba su capacidad de convocar a otros actores sociales y políticos, mostrando la validez y legitimidad que adquiere esta lucha migrante en la sociedad chilena. Así, en su acción colectiva los migrantes organizados han buscado alianzas con los movimientos sociales y la ciudadanía, buscando romper las fronteras del racismo y la exclusión que conforman nuestra sociedad. 


\section{Bibliografía}

Acevedo, P. Cobos, M. y von der Hunt, D. (2018) Derechos de las y los trabajadores migrantes. Estándares internacionales, legislación comparada y perspectivas en Chile. Observatorio Ciudadano, Fundación AVINA.

Avendaño, C. (1999) "Refugiados en Chile. Situación de los refugiados y solicitantes de Chile". Revista Migrantes, Instituto Católico de Migraciones, n57. pp. 32-36.

Bellard Quiroga, C. (2016) "Negritudes extranjeras en Chile. Significaciones y estereotipos sexogenéricos en la interacción de Inmigrantes afrocaribeñas(os) con chilenos (as)" En Racismo en Chile. La piel como marca de la inmigración, Editorial Universitaria, 2016, pp. 246-247.

Benhabib, S. (2005), Los derechos de los otros: extranjeros, residentes y ciudadanos, Barcelona: Gedisa.

Briones, C. (2005) Formaciones de alteridad: contextos globales, procesos nacionales y provinciales, Buenos Aires, Antropofagia Ediciones.

Bórquez, V. y Salvo, J. (2014) Comunidad y asociatividad migrante en Santiago de Chile (19902014). Un rescate de las experiencias de lucha y dignificación en organizaciones y asociaciones de migrantes, Tesis Licenciatura, Universidad de Chile.

Correa Tellez, J. (2008) Ser 'inmigrante' en Chile: La experiencia del racismo cotidiano de peruanos y peruanas en la ciudad de Santiago. Tesis Pregrado, Universidad de Chile, 2011.

Cortés del Castillo, Daniela. Ser niño inmigrante en Chile (Crecer en movimiento). Tesis Pregrado, Universidad de Chile.

Doña, C. (2002) Percepción de la inmigración reciente en Chile a través del análisis de prensa. Tesis Pregrado, Universidad de Chile, 2002.

Fernández Espinoza, B. y Herrera Milla, C. (2017) Inmigrantes y comunidades nacionales en contextos de neoliberalismo: la experiencia de la organización Fuerza Inmigrante en Chile. Tesis para optar al grado de Licenciatura en Historia, Departamento de Ciencias históricas, Universidad de Chile.

Figueroa Cornejo, A. (2014) "Trabajadoras migrantes de casa particular. Un abrazo de humanidad", Rebelión.org.

Guizardi, M. y Garcés, A. (2014) "Estudios de caso de la migración peruana en Chile: un análisis crítico de las distorsiones de representación y representatividad en los recortes espaciales", Revista de Geografía Norte Grande, N58.

Goldring, L. y Landlot, P. (2013) Producing and negotiating non-citizenship. Precarious legal satus in Canadá, Toronto, University of Toronto Press.

Hall, S. (2010) "La importancia de Gramsci para el estudio de la raza y la etnicidad". En: Stuart Hall, Sin garantías. Trayectorias y problemáticas en estudios culturales. pp. 257-285. Popayán-Lima-Quito: Envión Editores-IEP- Instituto Pensar-Universidad Andina Simón Bolívar, 2010. . (2003) "Pensando en la diáspora: en casa, desde el extranjero". En: Carlos Jáuregui y Juan Pablo Dabove (ed), Heterotropías: Narrativas e la identidad y la alteridad en Latinoamérica. pp. 476-500. Pittsburg: Instituto Internacional de Literatura Iberoamericana. 


\section{Bruno Rojas}

Jensen, María Florencia y Ximena Valdebenito. (2010) "De inclusiones y exclusiones: una perspectiva de la inmigración desde la Asociatividad en Chile", Miradas en Movimiento- MeM, vol. 3.

Lobos, D. (2017) Migración y trabajo doméstico: las trabajadoras inmigrantes asociadas en el SINAINCAP en Santiago de Chile, 2012-2017, Tesis Licenciatura, Universidad de Chile.

Luque Brazán, J.C. (2002a) Los caminos de la ciudadanía, entre el modelo nacional y el modelo postnacional. El caso de los inmigrantes peruanos en Santiago de Chile. Tesis Magíster. . (2002b) "Transnacionalismo y enclave territorial étnico en la configuración de la ciudadanía de los inmigrantes peruanos en Santiago de Chile". Revista ENFOQUES, $\mathrm{n}^{\circ} 3,2004$.

. (2007a) "Asociaciones políticas de inmigrantes peruanos y la 'Lima Chica' en Santiago de Chile”. Revista Migraciones Internacionales, vol. 4, n², El Colegio de la Frontera Norte, Tijuana, julio-diciembre.

- (2007b) "Los refugiados peruanos y sus asociaciones políticas en Santiago de Chile (1990-2006)”. E.I.A.L., vol. 20, nº1.

. (2009) “La producción de la ciudadanía en la era de la migración: el caso de las asociaciones políticas de los peruanos en Santiago de Chile (1996-2006)". Revista Ánfora, año 16, $\mathrm{n}^{\circ}$ 27, Universidad Autónoma de Manizales.

Martínez, J. (2008) América Latina y el Caribe: migración internacional, derechos humanos y desarrollo. CEPAL.

Mezzadra, S. (2005) Derecho de fuga. Migraciones, ciudadanía y globalización. Traficante de Sueños, Madrid.

Modonesi, M. (2016) El principio antagonista. Marxismo y acción política, İtaca-UNAM, 2016.

Portes, A. (1995) "Economic Sociology and the Sociology of Immigration: A Conceptual Overview", en Alejandro Portes, coord., The Economic Sociology on Immigration, Nueva York, Russell Sage Foundation. pp, 1-14.

Ramírez, C., Chan, C., y Stefoni, C. (2021) "Migraciones, etnicidades y espacios: aproximaciones criticas desde la etnografía". En Ramírez et al. Migraciones, etnicidades y espacios: aproximaciones críticas desde la etnografía, Ril Editores, Santiago, pp. 1137.

Riobó, E., Rojas, P. y Seward. P. (2019) “Migración en Chile: Notas para pensar el fenómeno desde la izquierda". Cuadernos de coyuntura, $\mathrm{n}^{\circ} 23$, abril.

Ruiz Encina, C. (2015) Carlos. De nuevo la sociedad. LOM Ediciones, Santiago. . (2020) Octubre Chileno. La irrupción de un nuevo pueblo, Taurus, Santiago.

Segura, D. y Bijit, K. (2014) "Barrios y población inmigrantes: el caso de la comuna de Santiago", Revista INVI, n॰81.

Stang, M. F. (2012) "Estado y migración internacional en el Chile de la posdictadura: una relación con cara de Jano". Sociedades de Paisajes Áridos y Semiáridos, año 4, n6.

Stefoni, C. y Fernández, R. (2011) "Mujeres inmigrantes en el trabajo doméstico. Entre el servilismo y los derechos". En: Mujeres inmigrantes en Chile ¿Mano de obra o trabajadoras con derechos?, (ed) Carolina Stefoni, Ediciones Universidad Alberto Hurtado, 2011.

Stefoni, C., Leiva, S. y Bonhomme, M. (2017) "Migración internacional y precariedad laboral. El caso de la industria de la construcción en Chile". REMHU: Revista Interdisciplinar da Mobilidade Humana. vol. 25, $\mathrm{n}^{\circ} 49$. 
Stefoni, C. \& Stang, F. (2017). La construcción del campo de estudio de las migraciones en Chile: notas de un ejercicio reflexivo y autocrítico. Íconos. Revista de Ciencias Sociales, (58), 109-129. https://dx.doi.org/10.17141/iconos.58.2017.2477

Stefoni, C. (2001) "Representaciones Culturales y Estereotipos de la Migración Peruana en Chile". Informe final del concurso: Culturas e identidades en América Latina y el Caribe. Programa Regional de Becas CLACSO. . (2004) "Inmigración y ciudadanía: la formación de comunidades peruanas en Santiago y la emergencia de nuevos ciudadanos”. Revista Política, n43, Universidad de Chile. . (2011a) "Ley y política migratoria en Chile. La ambivalencia en la comprensión del migrante". La construcción del sujeto migrante en América Latina. Prácticas, representaciones y categorías, compiladora Bela Feldman-Bianco, FLACSO; CLACSO y Universidad Alberto Hurtado.

. (2011b) Perfil migratorio de Chile. Organización Internacional para Migraciones. . (2017) "Panorama de la migración internacional en América del Sur.", Reunión regional latinoamericana y caribeña de expertas y expertos en migración internacional preparatoria del pacto mundial para una migración segura, ordenada y regular, CEPALOIM.

Tarrow, S. (2012). El poder en movimiento: Los movimientos sociales, la acción colectiva y la política. Alianza Editorial: España.

Tapia Landia, M. y Concha Liberona, N. (2018) "Presentación de la Red Nacional de Organizaciones Migrantes y Pro-Migrantes de Chile”. El afán de cruzar fronteras. Enfoques transdisciplinarios sobre migraciones y movilidad en Sudamérica y Chile, RIL editores.

Thayer, L. E. (2015) “Territorio, democracia en crisis y migración transnacional: el Estado de Chile frente a la nueva pluralidad social". Las fronteras del transnacionalismo. Límites y desbordes de la experiencia migrante en el centro y norte de Chile, editora María Guizardi, OCHO Libros, Universidad de Tarapacá. . (2016) "Migración, Estado y seguridad. Tensiones no resueltas y paradojas persistentes". Revista Polis, vol.15, n44.

Thayer Correa, Luis Eduardo. (2013). Expectativas de reconocimiento y estrategias de incorporación: la construcción de trayectorias degradadas en migrantes latinoamericanos residentes en la Región Metropolitana de Santiago. Polis (Santiago), 12(35), 259285. https://dx.doi.org/10.4067/S0718-65682013000200012

Tijoux, M. E. y Córdova Rivera, M.G. (2015) "Racismo en Chile: colonialismo, nacionalismo, capitalismo". Revista Polis, vol.14, n42.

Tijoux, M. E. (2011) "Negando al "otro": el constante sufrimiento de los inmigrantes peruanos en Chile”. Mujeres inmigrantes en Chile ¿Mano de obra o trabajadoras con derechos?, editora Carolina Stefoni, Ediciones Universidad Alberto Hurtado. . (2013) "Políticas migratorias, aspectos culturales, identidad y lucha contra la xenofobia”, Políticas públicas: exigibilidad y realización de derechos, editora Ximena Erazo, LOM ediciones. . (2016) Racismo en Chile. La piel como marca de la inmigración, Editorial Universitaria, 2016, pp. 246-247.

Van Deth, J. W. (2001) "Studying political participation: towards a theory of everything?" Trabajo presentado en la Joint Session of Workshops of the European Consortium for Political Research, Grenoble, Francia. 
Varela, A. (2015) "Luchas migrantes": un nuevo campo de estudio para la sociología de los disensos. Andamios. Volumen12, número 28, mayo-agosto, pp. 145-170.

Zapata, Claudia. (2008) "Edward Said y la otredad cultural”. Revista Atenea, Concepción, n. 498, p. 55-73.

Documentos

Bazo, Francisco. (2004) “La visión desde los migrantes. El desafío de la solidaridad: los migrantes peruanos en Chile". Encuentro Perú-Chile.

Boletín Comité de refugiados peruanos y Fuerza Inmigrante. (2014) Año 3, Nº1, diciembre, 2014.

Boletín Comité de Refugiados Peruanos en Chile y Fuerza Inmigrante. (2014) Año 3, N¹0, 2014.

Colectivo Sin Fronteras. Cartilla de derechos de niños y niñas en situación de migración, Chile.

MAM, "Declaración de organizaciones ante anuncios del Ejecutivo del 9 de abril" http://www.mamchile.cl/?p=586

Ministerio de Educación. (2005) Oficio Ordinario $N^{\circ} 7 / 1008$ (1531). Ministerio de Educación.

Ministerio del Interior. (2003) Oficio Circular $N^{\circ} 1179$. Departamento de Extranjería y Migración. Ministerio del Interior, 2003.

Ministerio de Relaciones Exteriores. (2005) Decreto $N^{\circ} 84$. Biblioteca del Congreso Nacional de Chile, 2005.

SINAINCAP. (2012a) Declaración, Santiago, abril.

SINAINCAP. (2012b) Invitación, Santiago, 11 de noviembre. Disponible en: https://www.facebook.com/photo.php?fbid=4991107740654\&set=g.139480892851864 \&type $=1 \&$ theater\&ifg $=1$

Warmipura. (2012). “Desterremos la intolerancia!!!”, Entre Mujeres, n³, mayo de 2012.

Audiovisual

Noriega, Rodolfo. (2015). Convocatoria a Movilización Mundial de Migrantes, 1 de Mayo 2015. [Vídeo online]. Disponible en https://www.youtube.com/watch? $\mathrm{v}=\mathrm{wlu} 42 \mathrm{Bsd} 11 \mathrm{I}$

Toro, Camila. (2015) "No, No, No nos CALLARÁN" Fuerza Inmigrante, 31 de mayo. [Vídeo online]. Disponible en https://www.youtube.com/watch?v=cwVkef2hbCs 